\title{
A NOTE ON WEYL'S INTERLACING INEQUALITY
}

\author{
MANDEEP SINGH AND JASPAL SINGH AUJLA
}

Abstract. We shall prove Weyl's interlacing inequality on one dimensional perturbation of Hermitian matrices using fundamental techniques.

Mathematics subject classification (2000): 15A42, 15A45, 47A63.

Key words and phrases: Interlacing eigenvalues inequality, perturbation of Hermitian matrices.

\section{REFERENCES}

[1] R. Courant AND D. Hilbert, Methods of Mathematical Physics, Willy, 1953.

[2] P. J. DAVIS, Interpolation and Approximation, Dover, New York, 1975.

[3] W. F. Donoghue, Monotone Matrix Functions and Analytic Continuation, Springer-Verlag, 1974.

[4] LORD RAYLEIGH, The Theory of Sound, reprinted by Dover, 1945. Originally published 1877.

[5] M. ReEd AND B. Simon, Methods of Modern Mathematical Physics, Volume 4, Academic Press, 1978.

[6] H. VASUdEVA, One dimensional perturbations of compact operators, Amer. Math. Soci., 57 (1), 58-60, 1976.

[7] H. VAsudeVA, One dimensional perturbations, Indian J. Pure and Appli. Math., 10 (6), 745-751, 1979. 